\title{
Powder Particles and Technologies for Medicine Delivery to the Respiratory System: Challenges and Opportunities ${ }^{\dagger}$
}

\author{
Tomasz R. Sosnowski \\ ${ }^{1}$ Faculty of Chemical and Process Engineering, Warsaw University of Technology, Poland
}

\begin{abstract}
The paper discusses essential engineering challenges related to the application of powder medicines for pulmonary delivery as inhaled aerosol. Starting from a physically based description of the complexity of aerosol dynamics inside the respiratory system, the paper discusses several technical factors responsible for efficient drug delivery to the lungs: (i) interparticle interactions - which can be tuned by selection and control of powder manufacturing methods, (ii) inhaler design - as a determinant of flow dynamics through the inhaling device and degree of powder dispersion, (iii) the dynamics of inhalation in a given inhaler - which is related to patient-device interaction. Basic information on the standard (compendial) methods of the quantitative evaluation of dry powder inhalers (DPIs) are presented with a special focus on the correct data interpretation and the consequences for in vivo-in vitro correlation (IVIVC) problems. Some issues regarding the development of inhalation products (including generics) are also briefly highlighted. Finally, possible strategies of powder particle functionalization to obtain the required bioavailability are outlined on the basis of knowledge on the physicochemical interactions of inhaled particles with the lung fluids.
\end{abstract}

Keywords: inhalation, lung deposition, DPI, flow dynamics, mucus, pulmonary surfactant

\section{Introduction}

The idea of using aerosol particles as drug carriers comes from the ancient times when the inhalation of smoke and fumes from burned plants appeared to induce favorable health effects (Sanders M., 2011; Stein S.W. and Thiel C.G., 2017). In modern times, it has been realized that the atomization of medicinal liquids to very small droplets helps to transfer them to the respiratory system beyond the upper airways (mouth and throat). Such a possibility of drug targeting to specific lung regions provided the opportunity to treat pulmonary diseases locally with low overall drug mass and minimized side effects. It also became clear that aerosolized drugs need not necessarily be a liquid, but can also be in the form of fine particles of solids.

The technical possibility of using dry powders as vehicles of drugs carried into the respiratory system is the topic of this paper. This apparently simple idea of drug delivery covers non-trivial challenges and many physical limitations which need to be overcome if a reproducible drug dose is to be delivered from a portable and inexpensive inhaling device.

This analysis starts with the overall characteristics of physical phenomena related to aerosol inhalation and particle deposition in the lungs. Next, the major challenges of aerosol formation in inhaling devices are discussed with the main focus on the proper design of dry powder inhalers (DPIs) and on the properties of powders as precursors of inhalable aerosols. The dynamic aspects of the above-mentioned problems are highlighted because very often they are ignored in the analysis of particle deposition in the lungs and powder inhaler performance. Some essential information on aerosol evaluation using the compendial (pharmacopeial) methods is also presented, indicating their limitations which can lead to the inaccurate interpretation of data. Finally, some facts regarding physical aspects of interactions between deposited particles and the lung surface are discussed to show the relationships between particle properties and drug bioavailability. All presented data make it possible to highlight potential new opportunities of inhalation therapy with the use of powder particles.

$\dagger$ Received 7 June 2017; Accepted 9 August 2017

J-STAGE Advance published online 30 September 2017

Waryńskiego 1, 00-645 Warsaw, Poland

E-mail: tomasz.sosnowski@pw.edu.pl

TEL: +48-22-234-6278 FAX: +48-22-825-1440 
Main benefits and drawbacks of drug delivery by aerosol inhalation.

\begin{tabular}{lc}
\hline \multicolumn{1}{c}{ Benefits } & Drawbacks/limitations \\
\hline $\begin{array}{l}\text { 1. Drug delivered directly to the } \\
\text { expected site of action in the } \\
\text { respiratory system: the dose can } \\
\text { be minimized, low side effects }\end{array}$ & $\begin{array}{l}\text { 1. Uncertainty of dose } \\
\text { delivered locally to the } \\
\text { target area }\end{array}$ \\
$\begin{array}{ll}\text { 2. Low enzymatic drug deactiva- } \\
\text { tion in the lungs: the dose can } \\
\text { be minimized }\end{array}$ & $\begin{array}{l}\text { 2. Technical challenges } \\
\text { related to drug formu- } \\
\text { lation, dosing and } \\
\text { aerosolization }\end{array}$ \\
$\begin{array}{ll}\text { 3. Non-invasive, pain-free and } \\
\text { easy-to-use method of drug } \\
\text { delivery }\end{array}$ & $\begin{array}{l}\text { 3. Patient-dependent } \\
\text { efficiency of drug } \\
\text { delivery }\end{array}$ \\
\hline
\end{tabular}

\section{Basic concepts and the physics of inhalation drug delivery}

\subsection{Drug inhalation as a unique method of pharmacotherapy}

Drug delivery by the inhalation of aerosolized medicines is a therapeutic method which has several advantages but also some essential drawbacks (Table 1).

The main benefit is related to minimization of the dose which needs to be introduced to the organism to produce the expected concentration in the target site (i.e. on the surface of the respiratory system). For inhalation devices (inhalers), it is often enough to deliver only several micrograms of the active pharmaceutical ingredient (API) to result in the local lung dose comparable to almost one hundred milligrams delivered by injection or tablets (Alangari A.A., 2014). With a natural and painless application mode, inhalation therefore presents a safe and convenient method of pharmacotherapy. On the other hand, unlike other drug delivery systems (tablets, pills, injections), the inhalation of aerosolized medicine does not guarantee precise dosing. The reason is that none of the sequential processes of aerosol generation, aerosol evacuation from the inhaler and regional deposition in the respiratory system is $100 \%$ efficient, which means that only a fraction of the drug initially loaded to the inhaler can be transferred to the target area, Fig. 1. Moreover, this number is noticeably variable since it depends both on the performance of the inhaling device and on the patient's individual capabilities to use it correctly, Fig. 2. As stated earlier, there is a long list of technical problems which need to be solved to achieve a reliable and reproducible drug delivery system based on powder inhalation, and they will be addressed herein.

It is obvious that not all aerosol particles can be used as effective drug carriers. To play that role, particles must be inhalable, i.e. small enough to be drawn with air into the

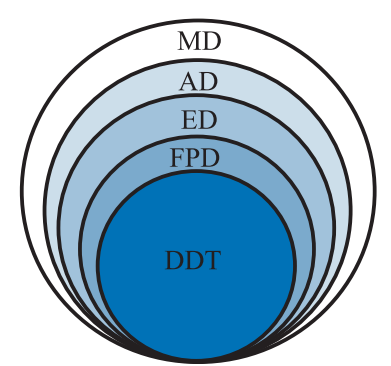

Fig. 1 General relationship between the nominal (metered) dose-MD, aerosolized dose-AD, emitted dose-ED, fine particles dose-FPD and dose deposited at the target-DDT.

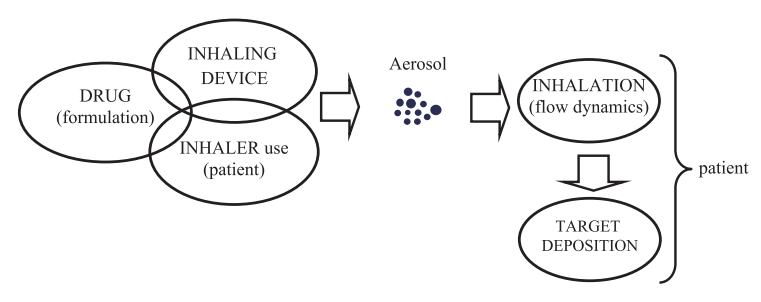

Fig. 2 Schematic path from the drug to target deposition.

mouth or nose. Moreover, they must be capable of penetrating beyond the naso-oro-pharynx and the upper bronchial tree so they can reach the lower respiratory system and settle there

Interestingly, the preferred deposition region may be different for various types of inhaled drug, since the occurrence and surface density of cellular receptors for drug binding/stimulation differs along the walls of the bronchial and pulmonary airways (Howarth P.H., 2001; Barnes P.J., 2004; Usmani O.S. et al., 2005; Pirożyński M. and Sosnowski T.R., 2016). For instance, muscarinic receptors (e.g. M3) are located mainly in the central airways, so the relevant drugs (bronchodilating cholinergic antagonists) should be preferentially delivered to these lung regions. The distribution of the receptors for beta2-mimetics requires the deposition of such drugs both in the central and distal respiratory tract, although the alveolar region can be omitted since no bronchodilating effect is expected there. Glucocorticoid receptors (GRs) are distributed all over the lower respiratory system, but steroids should not penetrate in large amounts into the lung periphery since we want to avoid their undesired absorption into the circulation from alveoli. It is therefore clear that different aerosol drugs can be formulated differently to obtain the most desired therapeutic effects.

\subsection{Physics of aerosol particle flow and deposition in the respiratory tract}

The whole respiratory tract acts as a filter for inhaled aerosols where particle flow, penetration and deposition in the respiratory system are governed by general physical 


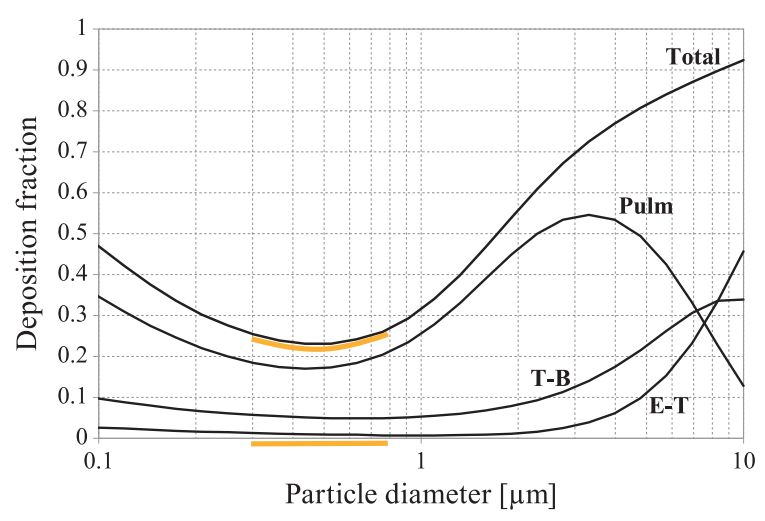

Fig. 4 Regional and total particle deposition in the respiratory system as a function of particle size-calculations based on the ICRP model and Multi-Path Particle Dosimetry software (MPPD, 2015) for deep and slow oral inhalation $(\mathrm{TV}=1500 \mathrm{ml}$, breathing cycle time $=12 \mathrm{~s}$ ). Lung regions: Pulm $=$ pulmonary (alveolar), $\mathrm{T}-\mathrm{B}=$ tracheobronchial, E-T $=$ extra-thoracic (airways of head and neck). The particle size range with the lowest deposition is highlighted. tor must be considered if we try to target any specific region with inhaled aerosol medicine (Zanen P., 2003; Kleinstreuer C. et al., 2008). Fig. 3 shows all particle deposition mechanisms which are believed to predominate in respiratory airways.

Particles with a high momentum (mass $\times$ velocity) hit the walls of the air ducts due to inertial impaction, mostly when the airflow rapidly turns. It takes place, e.g. in the mouth (hard and soft palate), throat and at bifurcations of large bronchi (Moskal A. and Gradoń L., 2002; Sosnowski T.R. et al., 2007). Particles which are able to penetrate these regions but have a relatively high mass can still fall gravitationally at an appreciable rate. Therefore, the chance of their penetration beyond the small bronchi, where aerosol residence time is extended due to a decrease of the average flow velocity, is minute. Moreover, the diameter of the airways in this region is reduced so the gravitational settling becomes effective. Submicron particles, which have a low inertia and also a negligible sedimentation rate, penetrate to the lung periphery to a greater extent. They can reach the airway walls of that region by Brownian diffusion.

Presented facts allow the development of quantitative methods for predicting particle deposition in various lung regions (Longest P.W. and Holbrook L.T., 2012; Tu J. et al., 2013). Different approaches to that problem are presented in the next section.

\subsection{Quantitative models of deposition of inhaled particles}

The deposition of inhaled drug particles can be quantitatively predicted by adaptation of the models which have been originally elaborated in the field of inhalation toxicology. Such semi-empirical models are often based on

the experimental data fitted by relatively simple mathematical formulae which can estimate the deposition of particles with different sizes and for variable breathing regimes. Such models (e.g. ICRP (Annals of the ICRP, 1994)) calculate only the regional deposition efficiencies (in the upper airways, tracheo-bronchial region, small bronchi or alveolar zone) which, by summing up, give also the total deposition in the whole respiratory system (Fig. 4).

Regional deposition can be derived also from other models which consider more precisely the predominating deposition mechanisms in various regions of the respiratory system. For instance, Finlay W.H. and Martin A.R. (2008) proposed mathematical formulae for the oropharyngeal region and the lower respiratory tract deposition, taking into account the residence time and the average local particle aerodynamics. In this model, the average Reynolds $(R e)$ and Stokes (Stk) numbers are used to generalize air and particle flow in the respiratory system.

A more detailed approach to the quantitative description of particle deposition is based on particle tracking during their flight through the respiratory airways. Reliable quantitative data regarding bronchial tree geometry (airway lengths, diameters and branching angles) are needed to predict the average airflow rates and particle behavior in each generation. Symmetrical or asymmetrical lung geometry can be used (Yeh H.C. and Schum G.M., 1980) where the first leads to a single path while the second leads to multipath trajectories of aerosol particle transport (Asgharian B. et al., 2001). In the multipath transport, a random choice of geometry is assumed resulting in a so-called stochastic lung deposition model (Koblinger L. and Hofmann W., 1990). 
din these models, the fractional deposition in each genenation of the bronchial tree can be calculated which gives more detailed information on drug distribution in the lungs.

It may be mentioned that some of the above-discussed models are accessible in the user-friendly calculators which are freely available on the Internet (MPPD, 2015; ARLA, 2008).

The most precise predictions of local particle dynamics and deposition can be obtained from detailed calculations of the particle trajectory within the numerically reconstructed geometry of the selected fragments of the respiratory system. It can be conveniently done applying computational fluid dynamics (CFD) methodology (Tu J. et al., 2013). Commercial packages help to predict the actual three-dimensional airflow field in the defined airway geometry by numerically solving the Navier-Stokes equation within the domain decomposed into finite volume elements. Even with the use of a commercial computational package, the task itself is not trivial and requires correct construction and optimized resolution of the numerical mesh followed by the application of a suitable solver with appropriate boundary conditions. Tracking of each particle in the airflow field is done by the Lagrangian approach, i.e. solving the mass balance of a single particle. The most general description combines both deterministic and stochastic forces acting on particles, the latter being associated with Brownian diffusion, i.e. particle motion caused by random collisions with air molecules. The Langevin equation which describes particle acceleration under such conditions takes the form (Moskal A., 2011):

$$
\frac{\mathrm{d} u_{\mathrm{p}}}{\mathrm{d} t}=-\frac{18 \mu}{\rho_{\mathrm{p}} d_{\mathrm{p}}{ }^{2}}\left(u_{\mathrm{p}}-u\right)+\frac{6}{\pi \rho_{\mathrm{p}} d_{\mathrm{p}}{ }^{3}} F_{\text {ext }}+\frac{6}{\pi \rho_{\mathrm{p}} d_{\mathrm{p}}{ }^{3}} F_{\mathrm{B}}
$$

where $u_{\mathrm{p}}$ and $u$ denote the velocity of particle and air, respectively, $d_{\mathrm{p}}-$ particle diameter, $\rho_{\mathrm{p}}$ - particle density, $\mu-$ air viscosity, $F_{\text {ext }}$ - external forces affecting the particle trajectory (gravity, electrostatic or magnetic interactions, etc.) and $F_{\mathrm{B}}$ - the Brownian force which plays a role mainly for submicrometer-size particles. For a spherical aerosol particle suspended in the air, the Brownian force is given by:

$$
F_{\mathrm{B}}=m_{\mathrm{p}} \alpha_{\mathrm{B}} \boldsymbol{Z}
$$

where $\alpha_{\mathrm{B}}$ is the characteristic magnitude of acceleration due to thermal excitation, and can be expressed as:

$$
\alpha_{\mathrm{B}}=\sqrt{\frac{2 \pi S_{0}}{\Delta t}}
$$

$S_{0}$ is a spectral intensity of a white noise which can be conveniently used to model the stochastic Brownian effects:

$$
S_{0}=\frac{216 \mu_{\mathrm{f}} k_{\mathrm{B}} T}{\pi^{2} d_{\mathrm{p}}^{5} \rho_{\mathrm{p}}^{2} C_{\mathrm{s}}}
$$

where $T$ is the absolute temperature, $k_{\mathrm{B}}$ is the Boltzmann constant, and $C_{\mathrm{s}}$ the Cunningham slip correction factor. $\boldsymbol{Z}$ in eq. (2) is the dimensionless vector with random direction and $\Delta t$ denotes the time step of numerical integration of the trajectory equation. It can be noted that the Brownian force acts on aerosol particles all the time but its direction and magnitude are randomly changed (through the random updating of value of $\boldsymbol{Z}$ ) at the end of every time step $\Delta t$. The presented method of numerical computations can be used to analyse particle motion in a human breathing system also at realistic non-steady-state flow conditions (Moskal A. and Gradoń L., 2002). Numerical solutions allow finding the trajectory of any particle of the defined size and properties, and eventually finding the place of particle deposition on the airway wall. If the computations are repeated many times for thousands of particles with various sizes, the results of particle deposition probability (i.e. deposition efficiency) in the analysed region is obtained as a function of the particle size.

As in any type of particle separation process (e.g. conventional air filtration), a certain particle size range exists where none of the previously mentioned mechanisms is sufficiently effective. Such particles (typically $0.3-$ $0.8 \mu \mathrm{m}$ ) can be exhaled without significant previous deposition in the respiratory system. In the example of the relationships of regional deposition efficiency vs. particle size shown in Fig. 4, the minimum of total deposition in the size range referred to above is clearly seen. Interestingly, some systems dedicated to aerosol delivery to the lungs may take advantage of a non-optimal deposition. For instance, e-cigarettes are designed in a way which allow a visible mist (typically composed of fine droplets of glycerine and propylene glycol) to be exhaled since this mimics the use of classic (i.e. tobacco) products. All droplets released from e-cigarettes are smaller than $2 \mu \mathrm{m}$ (mass median diameter $\sim 0.4 \mu \mathrm{m}$ ), for which the predicted deposition in the respiratory system is less than $50 \%$, independent of the breathing maneuver (Sosnowski T.R. and Kramek-Romanowska K., 2016).

\subsection{Aerosol dynamics and other factors influencing particle deposition during inhalation}

It is commonly agreed that the aerodynamic particle diameter $d_{\mathrm{a}}$ is the most suitable measure of the particle ability to penetrate and deposit within the respiratory system. The aerodynamic diameter is defined as:

$$
d_{\mathrm{a}}=d_{\mathrm{p}}\left(\frac{1}{\chi} \frac{\rho_{\mathrm{p}}}{\rho_{\mathrm{w}}}\right)^{0.5}
$$

where $\rho_{\mathrm{w}}$ denotes density of water, and $\chi$ the dynamic shape factor of the particle. Only particles with $d_{\mathrm{a}}<5 \mu \mathrm{m}$ are expected to be inhaled deeply to the bronchial tree where they eventually settle. Aerosol particle size distribution based on the aerodynamic diameter is typically 
assessed by standard compendial methodology using malli-stage (cascade) impaction separators: NGI (Next Generation Impactor), Andersen, Marple-Miller or impinging jet impactors (USP, 2008; European Pharmacopoeia, 2013). This type of determination of the aerosol particle size distribution is an indispensable step in the pharmaceutical development and validation of orally inhaled medical products (CHMP, 2009), and some details of such characterizations of aerosol drug particles will be discussed in section 3.3.

The aerodynamic diameter is a disputable criterion of particle behavior in the lungs if the particles are noncompact in shape, e.g. plate-like or needle-like, when interception can become the predominant deposition mechanism (Fig. 3). Moreover, the aerodynamic size properly describes the particle settling time under gravity or inertial forces, assuming that a particle is carried with air at constant velocity. In reality, it is obviously not true. Inhalation is a dynamic (time-dependent) process in which a certain volume of air is pumped through the airways at variable acceleration and deceleration. Therefore, the aerodynamic size has a different influence on particle behavior depending on the time-instant during inhalation. This complicates analysis of the processes of aerosol penetration and deposition in the respiratory system. In many theoretical and experimental analyses of aerosol inhalation and deposition, the constant flow rate is assumed (such as the mean flow of the inspiration, e.g. Matida E.Z. et al., 2004; Zhang Z. et al., 2005; Farkas A. and Balazhazy I., 2008; Ma B. and Lutchen K.R., 2009), which is an inaccurate simplification. Some studies show that particles in the realistic non-steady inhalation flow show dissimilar dynamics as compared to the constant flow conditions, and this leads to a different spatial distribution of particle deposition (Moskal A. and Gradoń L., 2002; Sosnowski T.R. et al., 2007). The influence of flow dynamics on particle deposition can be demonstrated by a simple example. Fig. 5 schematically shows the dynamics of the inhalation phase and the relationship between the temporal volumetric flow rate $Q(t)$ and two characteristic values - the mean flow:

$$
\hat{Q}=\frac{1}{t_{\mathrm{inh}}} \int_{0}^{t_{\mathrm{inh}}} Q(t) \mathrm{d} t
$$

and the maximum flow value, $Q_{\max }=$ PIFR (peak inspiratory flow rate). It is important to note that the flow value equal to $\hat{Q}$ occurs in reality only at two instants of time $\left(t_{1}\right.$ and $t_{2}$ ) during the whole inspiration.

The temporal dimensionless Stokes number, being an indicator of inertial deposition (impaction), is defined as:

$$
S t k=\frac{\rho_{\mathrm{p}} u d_{\mathrm{p}}{ }^{2}}{\mu L_{0}}
$$

where - in addition to already defined variables $-L_{0}$ de-

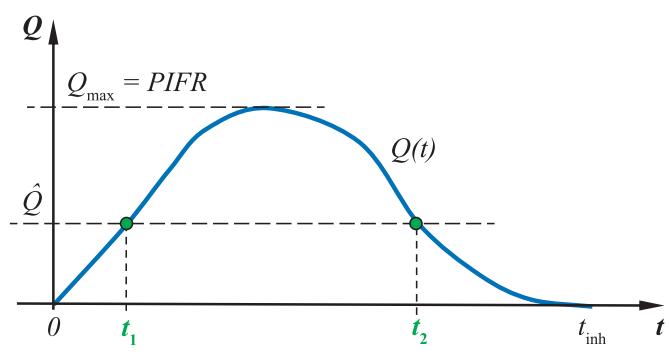

Fig. 5 Relationships between real flow dynamics $Q(t)$, average flow rate $\hat{Q}$ and the peak inspiratory flow rate (PIFR).

notes the characteristic local dimension of the airways. It can be easily seen that the same local value of the Stokes number is obtained if:

$$
u d_{\mathrm{p}}^{2}=\text { const } .
$$

Consequently, for a variable airflow rate during inhalation, a particle with $d_{\mathrm{p}}=10 \mu \mathrm{m}$ which moves at a velocity equal to the air velocity $u_{1}$ will be locally $\left(L_{0}=\right.$ const) deposited by impaction with the similar efficiency as a $5-\mu \mathrm{m}$ particle at the velocity $4 u_{1}$. The analogous analyses can be done also for other deposition mechanisms and they will show that at variable airflow, one cannot unambiguously link the regional deposition efficiency with the aerodynamic (or geometric) particle size.

The complexity of the description of dynamic behavior of inhaled powder particles in the lungs is additionally caused by other issues:

- in general, particles of medical aerosols are polydisperse;

- quite often powder particles are hygroscopic, so their actual size in the respiratory system will increase and their density will also be changed (Schum G.M. and Phalen R.F., 1997; Asgharian B., 2004; Winkler-Heil R. et al., 2014).

- particles at high concentrations may coagulate or move collectively in a so-called 'cloud motion' (Broday D.M. and Robinson R., 2003);

- bronchi and bronchioles are short-tubes, so inlet effects have an influence on the flow pattern-e.g. the secondary flows are formed (Zhang Z. and Kleinstreuer C., 2002; Fresconi F.E. and Prasad A.K., 2007);

- due to flow periodicity, the analysis based on the local flow regime (laminar/turbulent) according to the Reynolds number as a basic criterion is inadequate;

- in DPIs, particles can appear in different phases of inhalation which has an influence on their transport in the respiratory system (see section 3.2).

Flow dynamics influences not only the behavior of particles in the respiratory system but also the performance of inhaling devices (aerosol formation and emission). This problem will be discussed in section 3 . 
through the device must match the inhaling force of the patients) (Hoppentocht M. et al., 2014)—see section 3.2.

Several books, book chapters and review papers are focused on a variety of technical solutions required for drug delivery of aerosolized powders via inhalation (e.g. Dunbar C.A. et al., 1998; Zeng X.M. et al., 2000; Borgström L. et al., 2002; Vanbever R., 2003; Newman S. and Peart J., 2009; Hoppentocht M. et al., 2014; Berkenfeld K. et al., 2015; Carvalho S.R. et al., 2015; de Boer A.H. et al., 2017). Here we will highlight the critical issues. Assuming that aerosol particles within a certain size-range are required for effective lung treatment by inhalation, the following technical problems must be identified:

- raw powders with the required particle size and surface properties must be prepared. Fine aerosol particles cannot be obtained from a powder composed of large grains;

- in addition, the surface properties of powders must assure that particles are not too cohesive so that their flow, fluidization and de-agglomeration are easily obtainable in a given inhaling device (Zeng X.M. et al., 2000);

- such powders must allow the formation of reproducible inhalable API doses in the range of several to some hundreds of micrograms. This frequently requires blending the API grains with additional powder. Anhydrous lactose or lactose monohydrate particles are typically used as the excipient, and it must have an optimized particle size and surface properties to ensure flowability and the required de-agglomeration of the blend upon aerosolization (Pilcer G. et al., 2012);

- optionally, the suitable API powder can be prepared without the excipient (Healy A.M. et al., 2014). In that case, the powder should possess special properties which can be obtained by particle engineering methods (Kaialy W. and Nokhodchi A., 2015) — see section 3.1;

- powder properties must be stable during the typical shelf lifetime of pharmaceutical products (typically 3 years);

- the medical powder must be packed in capsules or blisters with suitable properties to guarantee their efficient emptying during inhalation (Martinelli F. et al., 2015). Another choice is the use of reservoir-type inhaling devices, when the powder dose is metered immediately prior to the inhalation (Islam N. and Gladki E., 2008);

- the inhaling device itself must be optimized in a way to ensure reproducible powder metering and aerosolization (emitted dose: ED, fine particle dose: FPD). At the same time, the device should be easy to use, ergonomic, mechanically resistant and inexpensive in production. Certain conditions must be met regarding the internal aerodynamic resistance of the inhaler (the airflow

\subsection{Essential properties of powders used in drug delivery by inhalation}

To be effective vehicles for inhaled drugs, powder particles must be de-agglomerated in the airflow to form micrometer-size particles as schematically shown in Fig. 6 The outcome of this process depends on inhaler design, applied flow rate and powder properties. This is why the pharmaceutical powder has to be properly prepared before it can be used as a drug carrier. The main cohesive interactions which act against powder redispersion are caused by van der Waals forces, electrostatic and capillary forces, by hydrogen bonds and mechanical interlocking due to surface roughness (Zeng X.M. et al., 2000; Ramachandran V. et al., 2015). These interactions depend not only on the particle properties and their preparation method, but also on the ambient conditions such as air humidity.

Strategies which are used to prepare powder particles with the properties that facilitate their de-agglomeration include: (i) controlling the surface smoothness of the particles (Chew N.Y.K. and Chan H.-K., 2001; Geller D.E. et al., 2011), (ii) increasing interparticle distance, e.g. by adding nanoparticles (Begat P. et al., 2005), (iii) changing the properties of the particle surface, e.g. by coating with, e.g. leucine, magnesium stearate or surfactants as force-control agents (Begat P. et al., 2009; Sosnowski T.R. and Gradoń L., 2010). It can be also be beneficial to use micrometer-size nanostructured (partly porous) particles instead of compact ones with the same size (Tsapis N. et al., 2002; Jabłczyńska K. et al., 2015). All these strategies can be used both for drugs prepared as interactive mixtures (API-excipient) and for excipient-free formulations. Inhalable particles can also be developed with API embedded in a polymer matrix with PLGA (poly(lactic-co-glycolide) acid) being the most common matrix builder (Liang Z. et al., 2014). This drug delivery system has the additional advantage of sustained drug release in the target area. We should also mention a novel concept of inhalation powders based on the application of solid lipid nanoparticles (SLN) and nanostructured lipid carriers (NLC) forming a dry lipid matrix which can be loaded with the API and transferred to the lungs from DPIs without additional excipients (Weber S. et al., 2014; Li Y.Z. et al., 2010).

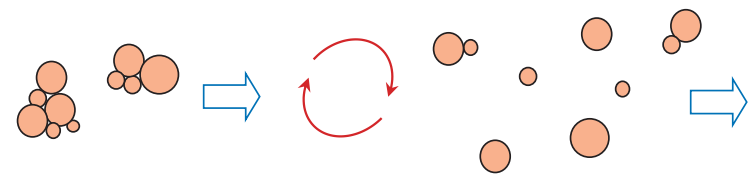

Fig. 6 De-agglomeration of powder drug in the airflow. 


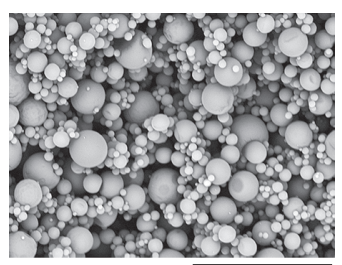

$20 \mu \mathrm{m}$

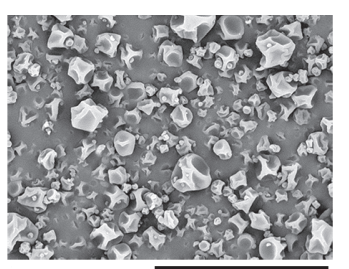

$20 \mu \mathrm{m}$

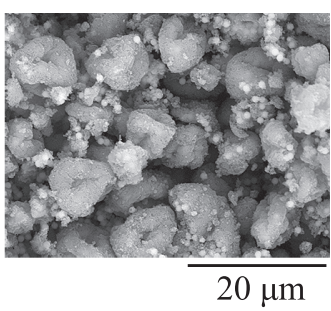

Fig. 7 Examples of different shape and structure of powder particles obtained by the controlled spray-drying of various precursors (unpublished SEM images from author's laboratory).

Spray drying, spray-freeze drying and enhanced crystallization/precipitation (ultrasonic-assisted or utilizing the supercritical fluid technology) are applied to obtain engineered powder particles. We will skip the detailed characteristics of these methods as their thorough description can be found elsewhere (Gradoń L. and Sosnowski T.R., 2014; Kaialy W. and Nokhodchi A., 2015). Due to the technological feasibility and easy scale-up, spray drying is probably the most convenient method of producing inhalable powders. It also allows control of the particle structure, size and aerosolization properties (Vehring R., 2008; Weers J.G. and Miller D.P., 2015). Correct selection of the composition and concentration of the precursor (i.e. liquid solution or suspension), as well as of the drying parameters are decisive in obtaining powders with the desired particle size and shape (Nandiyanto A.B.D. and Okuyama K., 2011; Kramek-Romanowska K. et al., 2011). Fig. 7 shows some examples of different powder structures which can be obtained by tuning the parameters of the spray-drying process into a conventional laboratoryscale device with pneumatic atomization of liquid precursors.

\subsection{Inhaler design and performance}

In all powder inhaler devices, aerodynamic stresses are used to fluidize the powder and de-agglomerate particle clusters to maximize the number of individual fine particles. The majority of DPIs currently available in the market belong to so-called 'passive' devices (Islam N. and Gladki E., 2008), where the aerosol is formed solely due to powder interaction with the flow generated by the patient's inhalation. In all such devices it is necessary to maximize the transfer of airflow energy to the powder, possibly without useless dissipation. This can be effectively done by the creation - in a logical way - of local turbulence or other effects such as flow focusing or fluctuations (Gac J. et al., 2008; Sosnowski T.R. et al., 2014). However, flow arrangements of this type always increase the aerodynamic resistance (the pressure drop) in the inhaler, so the final design of a DPI must be optimized. It is important to note that erroneous concepts of aerosolization chambers can result in completely inefficient powder

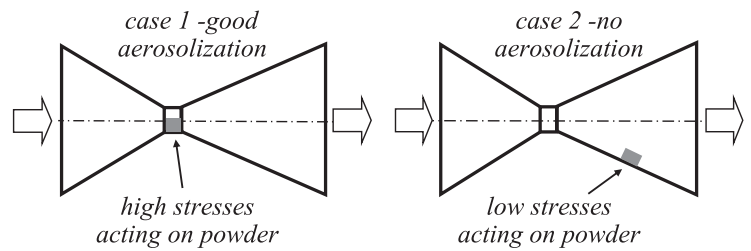

Fig. 8 Comparison of two hypothetical aerosolization systems with the same aerodynamic resistance but disparate dispersion efficiencies due to a different location of the powder layer (grey rectangle).

redispersion. This obvious rule is shown schematically in Fig. 8 by presenting two hypothetical inhaler chambers of identical design and aerodynamic resistance, but with totally different performance regarding the aerosol emission.

Aerodynamic resistance of the inhaler is a very important issue which needs to be well understood since it often leads to ambiguities. The intrinsic inhaler resistance is defined by the equation (Clark A.R. and Hollingworth A.M., 1993):

$$
R_{\mathrm{D}}=\frac{\sqrt{\Delta P}}{Q}
$$

where $\Delta P$ denotes the pressure drop (typically in $\mathrm{hPa}$ ) and $Q$ the volumetric airflow rate (typically in liters per minute, $\mathrm{L} / \mathrm{min})$.

Eq. (9) can be derived from the well-known relationship describing the local pressure drop:

$$
\Delta P=\gamma \frac{\rho u^{2}}{2}
$$

where $\gamma$ denotes the local resistance coefficient, which can be assumed independent of the airflow rate in the range relevant to inhalation $(30-120 \mathrm{~L} / \mathrm{min})$. This equation can be rewritten as:

$$
\Delta P=\frac{\gamma \rho}{2}\left(\frac{Q}{A}\right)^{2}
$$

where $A$ denotes the cross-sectional area for the airflow. After substituting:

$$
R_{D}^{2}=\frac{\gamma \rho}{2 A^{2}}
$$


given (rather short) period of the inhalation. Let us recall the flow curve already shown in Fig. $\mathbf{5}$ to analyse this process. Two different situations are depicted in Fig. 9. Assuming that the two DPIs denoted as 1 and 2 have a similar aerodynamic resistance but a different principle of powder release, we can see that the aerosol is emitted from inhaler 1 during time period $t_{1} \div t_{1}$, but from inhaler 2 during time period $t_{2} \div t_{2}$. Fig. 9a shows the corresponding flow rate, i.e. inhalation curve, while Fig. 9b shows the corresponding volume of air aspirated to the lungs.

Let us note that aerosol is emitted from inhaler 1 during a short period which is finished at $t_{1}$, i.e. before the maximum flow rate $Q_{\max }$ is achieved. In contrast, inhaler 2 is activated later (at $t_{2}$ ) by the flow rate close to $Q_{\max }$ and the release time is longer, so the aerosol is introduced to the air stream until $t_{2}$, which is not far from the end of inhalation, $t_{\text {inh. }}$. It can be expected that the quality (size distribution) of aerosol produced at higher flow rates, i.e. in case 2 , will be more favorable than in case 1 .

The graph of inhaled volume (Fig. 9b) shows that when the aerosol is totally emitted from inhaler 1 , the remaining volume of air to be inhaled is still large $\left(V_{\mathrm{rl}}\right)$, which means that the released particles can be carried even to the lung periphery. In contrast, after the entire dose of aerosol is released from inhaler 2 (at $t_{2}$ ), a small volume of air $V_{\mathrm{r} 2}$ remained for inhalation, so probably these particles can penetrate only the very first generations of the bronchial tree before the exhalation will begin.

The presented example shows another, often overlooked, factor which should be considered for the rational their performance on the flow rate is lower. Concluding this analysis, it may be stated that there should be an optimum of flow resistance in DPIs. The flow must be restricted to produce the high aerodynamic stresses required for good aerosolization of the powder, however, if the overall resistance of the device is too high, it can exclude a large group of patients from proper use of such device. Elimination of the problem of DPIs flowdependence is achieved in 'active' DPIs which utilize, for instance, the compressed gas to facilitate powder deagglomeration to fine particles. More than a decade ago, Exubera $^{\circledR}$ was developed as an active DPI for insulin delivery, however-due to various reasons - it was withdrawn from the market in 2007 (Heinemann L., 2008). Another active DPI-Spiromax ${ }^{\circledR}$ — has emerged recently for the delivery of drugs for asthma and COPD patients (Canonica G.W. et al., 2015).

Similarly to particle deposition in the lungs, drug inhalation from passive DPIs is a dynamic process. The aerosol is formed and released from the device during the

(a) $Q$

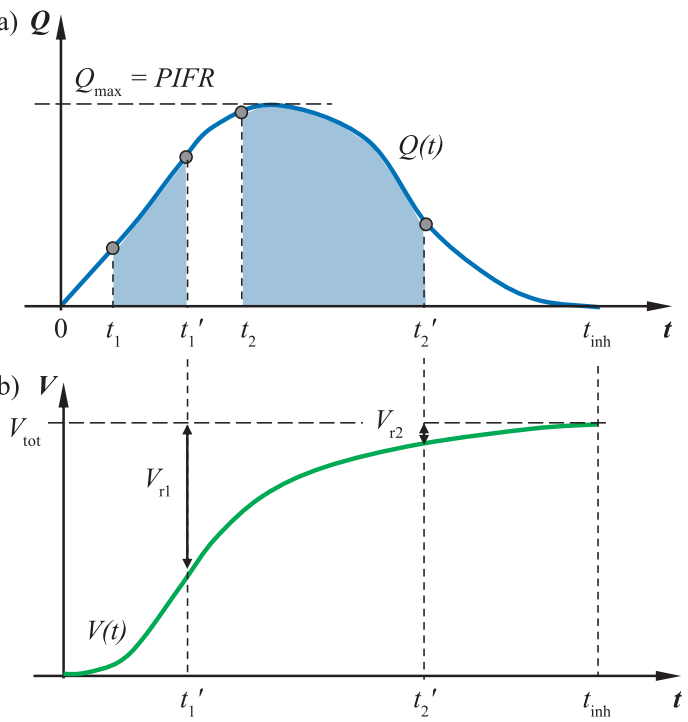

Fig. 9 (a) Inhalation curve $Q(t)$ and periods of aerosol release (gray fields) for two DPIs; (b) the corresponding inhaled volume curve $V(t)=\int Q(t) \mathrm{dt}$ and indicated remaining volumes of air inhaled after complete release of aerosol from both DPIs $\left(V_{\mathrm{r} 1}\right.$ or $\left.V_{\mathrm{r} 2}\right)$. 
Signeff inhalation systems based on powder redisper-

\subsection{Understanding the compendial methods of aerosol characterization}

Aerosol particles of medicines intended for inhalation must be evaluated by specialized methods to confirm that they have the proper size characteristics and reproducibility (USP, 2008; European Pharmacopoeia, 2013). Use of impactors instead of other measuring techniques is necessary because the majority of formulations contain particles with different chemical composition, e.g. in DPIs based on API-lactose blends or in combined products (two or more drugs delivered in one inhalation). In such cases, optical methods which are typically used for aerosol assessment (e.g. time-of-flight or light scattering/light diffraction) cannot be used because they do not distinguish particles that carry different chemicals. Since only the mass of API is of interest from the therapeutic perspective, all other particles should be ignored in such analyses. Cascade impactors can sort particles into several (typically 5-8) size classes based on their inertial deposition which is caused by flow acceleration at the consecutive separation stages. In the testing of DPIs, the aerosolized drug is drawn to the impactor via the inlet and the additional vessel (preseparator) capable of capturing large grains of the excipient which usually also contains some API is attached. Impactor inlet and preseparator are believed to mimic the upper airways (mouth and throat), however, the particle separation efficiency of these impactor elements is not strictly defined. Material collected at each stage of the impactor is then quantified by sensitive chemical assays - typically high-performance liquid chromatography (HPLC) - against the pharmacopeial standard of the API under test. Chromatographic analysis ensures that the API concentration is evaluated selectively and assigned to the given size class of particles captured at each separation stage. Thanks to this technique, the size distribution based on drug mass is obtained, which allows finding the most important indicators of the quality of medical aerosol: fine particle dose (FPD), fine particle fraction (FPF) and mass median aerodynamic diameter (MMAD). Due to their principle of operation, all impactors classify particles based on their aerodynamic size $d_{\mathrm{a}}$ defined by equation (5). Assuming a quasi-spherical particle shape and density in the range of $800-1200 \mathrm{~kg} / \mathrm{m}^{3}$, the aerodynamic particle diameter is almost the same $( \pm 10 \%)$ as the geometric diameter, $d_{\mathrm{p}}$. However, these two diameters can be very different in the case of, e.g. porous particles with an effective density in the range of hundreds of $\mathrm{kg} / \mathrm{m}^{3}$. In such cases, large particles (larger than $10 \mu \mathrm{m}$ ) may still be effective as drug carriers for inhalation since their aerodynamic behavior and inertial deposition is equivalent to smaller particles with a typical density.

There are two major drawbacks to impactor particle size analysis:

- the size resolution is limited to only 8 classes which are variable if the flow imposed during different assays is not the same;

- the measurements are time-consuming, expensive and sensitive to human factors. Errors can easily be made due to an extensive number of manual operations (assembly/disassembly of the impactor, pipetting, labware handling, impactor cleaning, etc.)

Until the Next Generation Impactor (NGI) was developed, inhalers could be tested only at several standard airflow rates (e.g. 28.3, 60 and $90 \mathrm{~L} / \mathrm{min}$ in the Andresen cascade impactor) due to a lack of certified calibration for other flows. The NGI allows characterization of the aerosol particle size at any flow rate in the range of 30-100 L/min, but also at lower values (down to $15 \mathrm{~L} / \mathrm{min}$ ). The aerodynamic cut-off size, $d_{\mathrm{c} i}$, at each stage $i$ depends on the applied flow rate and for $30-100 \mathrm{~L} / \mathrm{min}$, they can be calculated from the equation:

$$
d_{\text {ciat } Q}=d_{\text {ciat } 60 \mathrm{LPM}}\left(\frac{Q}{60}\right)^{x i}
$$

where $x i$ is the unique exponent for the given separation stage (MSP Corporation, 2008). A slightly modified correlation is valid for flow rates in the range $15-30 \mathrm{~L} / \mathrm{min}$. Cut-off sizes for selected airflow rates are listed in Table 2.

As seen from Table 2, the NGI cannot determine the size of particles larger than those captured at stage no. 1, and this maximum diameter depends on the flow rate applied during DPI testing. According to the standard, the mass median aerodynamic diameter (MMAD), which is often considered the important parameter in comparing different inhalation products, is calculated only taking into account the drug particles within the range of cut-off sizes specified for the numbered stages, thus ignoring the API mass collected inside the inlet port and preseparator. This leads to a risk of misinterpretation of the experimen-

Table 2 Nominal cut-off sizes $[\mu \mathrm{m}]$ for NGI impactor at selected airflow rates $[\mathrm{L} / \mathrm{min}]$.

\begin{tabular}{ccccc}
\hline Stage no. & $15 \mathrm{~L} / \mathrm{min}$ & $30 \mathrm{~L} / \mathrm{min}$ & $60 \mathrm{~L} / \mathrm{min}$ & $90 \mathrm{~L} / \mathrm{min}$ \\
\hline 1 & 14.1 & 11.7 & 8.06 & 6.12 \\
2 & 8.61 & 6.40 & 4.46 & 3.42 \\
3 & 5.39 & 3.99 & 2.82 & 2.18 \\
4 & 3.30 & 2.30 & 1.66 & 1.31 \\
5 & 2.08 & 1.36 & 0.94 & 0.72 \\
6 & 1.36 & 0.83 & 0.55 & 0.40 \\
7 & 0.98 & 0.54 & 0.34 & 0.24 \\
\hline
\end{tabular}


tatedata Since the range of particle sizes used for calculation of the MMAD depends on the applied flow (Table 2), it will be incorrect to compare the MMAD obtained for DPIs characterized by different resistance, $R_{\mathrm{D}}$. According to the standard, they must be compared at the same pressure drop $(4 \mathrm{kPa})$, hence at different flow rates. As particles eliminated before stage no. 1 are not considered in the mass balance, then it is possible to achieve a low MMAD (apparently a good value) even if a large amount of aerosol drug is contained in big particles deposited in the impactor inlet port and preseparator, as shown in Fig. 10. Therefore, the MMAD should be considered rather as a quality parameter which allows verification if different batches of a given inhalation product (i.e. with a given DPI) deliver - at the fixed airflow rate-the aerosol with a similar particle size distribution. According to the presented discussion, it is incorrect to use MMAD as a criterion of comparison of different DPIs and drugs.

The troublesome aerosol particle sizing by cascade impactors can sometimes be replaced by fast and accurate optical on-line measuring techniques such as laser diffraction, however, only under certain conditions. These methods can be used, e.g. in carrier-free DPIs which aerosolize only a single API. It is also reasonable to apply optical methods for pMDIs (pressurized metered dose inhalers), SMIs (soft mist inhalers) and nebulizers, assuming that all particles/droplets have a statistically identical composition. In such cases, they contain the API mass which is proportional to the cube of the particle diameter. For aqueous droplets $\rho_{\mathrm{p}} \approx \rho_{\mathrm{w}}$, according to eq. (5), we will directly obtain the aerodynamic diameter. For other materials, the geometric diameters $d_{\mathrm{p}}$ can be easily recalculated to $d_{\mathrm{a}}$ if the material density is known. Although optical methods are not compendial, for some inhalers (e.g. nebulizers), they have been demonstrated to be equivalent to pharmacopeial impactors (Kwong W.T.J et al., 2000; Ziegler J. and Wachtel H., 2005; Mao L. et al., 2010).

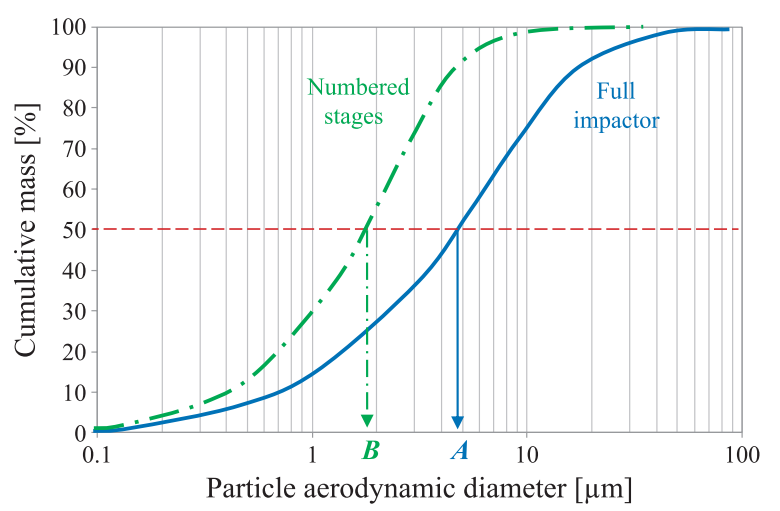

Fig. 10 Comparison of the real MMAD (A) of the aerosol and the MMAD calculated only on the basis of particles in the range limited to $0-11.70 \mu \mathrm{m}$, i.e. the sizes classified inside the NGI at $60 \mathrm{~L} / \mathrm{min}$ (B).

\subsection{In vitro-in vivo correlation (IVIVC) problem in aerosol inhalation}

The aerodynamic size of drug particles is needed not only to verify the reproducibility of the inhalation product (quality assurance) but also to confirm that the drug can be expected to effectively penetrate to the target region in the respiratory system. FPD $\left(d_{\mathrm{a}}<5 \mu \mathrm{m}\right)$ informs about the dose which has the best chance to reach the lower airways (USP, 2008; European Pharmacopeia, 2013). However, the applicability of this criterion is still discussed within the issue of IVIVC, i.e. in vitro-in vivo correlation (Clark A.R. and Borgström L., 2002; Newman S.P. and Chan H.-K., 2008). This problem tries to find a possibly precise link between the particle size of inhaled drugs and the expected health benefit and must, in fact, acknowledge the complexity of particle deposition discussed in section 2 . Some researchers claim that the mass of extra-fine particles $(1-3 \mu \mathrm{m})$ is more relevant to the real deposition and health effects (de Boer A.H. et al., 2015). However, as shown in Fig. 4, it is difficult to unequivocally indicate the optimum particle size, in particular considering intersubject variability in inhalation flow dynamics and airway geometry where both can be additionally altered in lung disease. Mitchell J. et al. (2007) additionally pointed out that the clinical response (the real in-vivo effect) will depend not only on the actual deposition of drug particles but also on the drug potency and the severity of lung disorder. These authors also discussed other limitations of application of the results of aerodynamic particle sizing to predict the regional aerosol deposition in the respiratory system. Cascade impactors are the technical devices which operate at ambient temperature and at a constant flow rate, which is a completely different situation compared to real aerosol inhalation. Laboratory testing conditions may influence the particle size distribution, e.g. due to evaporation of nebulized droplets (Zhou Y. et al., 2005) or additional deagglomeration of powders (Sosnowski T.R., 2008), which make such aerosols incomparable with the ones entering the lungs during drug inhalation. Although some additional technical improvements of cascade impactors have been proposed such as a more realistic mouth-throat model instead of the standard inlet (Copley M. et al., 2011), the problem of a direct conversion of the measured particle size to the real in-vivo drug delivery and efficacy still remains unsolved (Clark A.R. and Borgström L., 2002; Mitchell J. et al., 2007).

\subsection{Innovative and generic drugs development}

At the end of the discussion of challenges and opportunities in using inhalable powders for drug delivery, we should take a short look at the problems of development of inhalable medical products. Completely new inhalation 
gohiceptes (i.e. the new molecules with new inhalers) require strictly defined, demanding and expensive procedures to become a candidate for the medial product. In addition to precisely documented development steps, clinical studies to confirm the efficacy and safety are always required. Since many patents for therapeutic molecules are expiring, there is a trend to develop the generic products as cheaper substitutes of drugs originally developed some years ago. The procedure required to introduce a generic inhalation product to the market is simplified, and-according to some regulations (e.g. in Europe)clinical studies are not required if therapeutic equivalence is convincingly demonstrated (CHMP, 2009). Accordingly, the whole procedure is cheaper and faster, although there is concern whether such an approach is fully justified. It should also be noted that the legislation regarding generic inhalation products is different worldwide (Pirożyński M., and Sosnowski T.R., 2016). In any case, an important issue is the quality of the powder drug and the inhaling device, and both have to match the original product closely regarding the aerodynamic performance (e.g. DPI resistance) and the API aerosol size distribution obtained at different flow rates through the inhaler (CHMP, 2009).

Consequently, all key problems highlighted in the previous sections should be taken into account when the development of innovative or generic powder inhalation products is considered.

\section{Interactions of inhaled powders with lung surface - towards functional particles}

Powder properties should also be optimized regarding the bioavailability of the drug they carry into the lungs. Inhaled particles land on the wet surface of bronchi, bronchioles or alveoli, so they directly interact with the fluid layers of the lungs. In conducting airways, particles come into contact with mucus and the drug molecules eventually reach the epithelium after penetrating across the layer of this complex viscoelastic liquid. Deposited particles can be simultaneously transported along the airways due to the action of 'mucociliary escalator', i.e. the longitudinal flow propelled by beating cellular cilia (Smith D.J. et al., 2007). Since the underlying epithelium is the main target for inhaled bronchodilating and anti-inflammatory drugs, it is important to prepare the aerosol drug carriers in a way which facilitates API penetration through the mucus blanket. In diseased lungs, the mucus is abundant and more viscous (Cone R.A., 2009), so less permeable for inhaled drugs. In such a situation, inhalable powders with a specific composition and properties can be useful. According to a recent idea (Odziomek M. et al., 2012), the excipient particles might contain a mucolytic agent such as $\mathrm{N}$-acetylcysteine together with the stabilizing additive (e.g. dextran). Deposited particles of the drug bonded to such a carrier (in a similar way as in typical API-lactose blends) are capable of rheologically thinning the mucus due to interactions with the mucolytic agent which is released locally. This allows the drug to penetrate faster through the mucus layer (Odziomek M. et al., 2015). In the alternative concept, multicomponent powders combining both the mucolytic agent and the drug in a single particle were proposed (Gradon L. et al., 2009). The described functional particles can be effectively prepared by spray-drying through the adjustment of process conditions to obtain powders with good aerosolization properties. Mucus rheology and mass transfer phenomena in raw or modified mucus can be analysed by selected physicochemical methods (Schuster B.S. et al., 2013; Odziomek M. et al., 2017).

Particles deposited in the respiratory (alveolar) region interact not with the mucus but with the pulmonary surfactant (PS). The PS produced by type II alveolar cells contains lipids (mainly lecithins) and some unique proteins (Parra E. and Perez-Gil J., 2015). True to its name, the PS demonstrates strong surface-active properties. They have important consequences for lung physiology, due to:

- reduction of the work of breathing, i.e. the energy input required to expand during inspiration a large surface of the lungs $\left(\sim 100 \mathrm{~m}^{2}\right)$,

- several functions related to the lung clearance and improvement of other mass transfer processes in the pulmonary region (Sosnowski T.R., 2016).

It is important to note that PS is highly surface-active under the dynamic conditions of breathing, i.e. during oscillatory variations of the air/liquid interfacial area. Both temporal and spatial fluctuations of the surface tension along the interface take place due to surfactant mass exchange between the bulk liquid and the free interface, but also due to flow and diffusion at the interfacial boundary. Marangoni effects are generated due to the surface tension gradients providing the driving force for the hydrodynamic clearance of deposited particulates from the alveolar zone (Gradoń L. and Podgórski A., 1989; Gradoń L. et al., 1996) - Fig. 11.

Such behavior of the air-liquid interface can be reproduced in the laboratory using specialized measuring devices, e.g. Langmuir-Wilhelmy balance, oscillating bubble or oscillating drop tensiometers (e.g. Sosnowski T.R. et al., 2017; Kondej D. and Sosnowski T.R., 2013; Kondej D. and Sosnowski T.R., 2016; Wüstneck R. et al., 2002). These experimental systems allow determination of the dynamic surface tension variations during the breathing-like compression and expansion of the interface with the PS. Experimental measurements can also directly demonstrate the occurrence of the Marangoni flows in- 


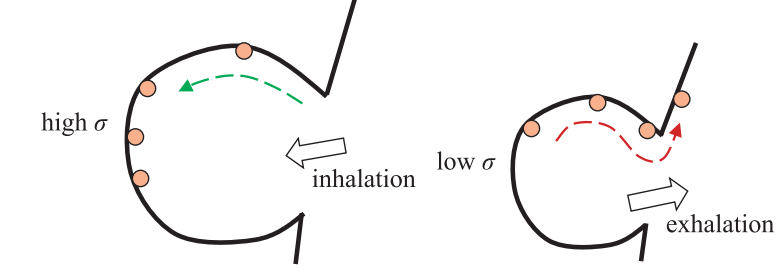

Fig. 11 Dynamic surface tension in alveolar region. Marangoni flows and particle transport are due to dynamic surface tension gradients $\nabla \sigma(t)$.

duced by the variations of interfacial area. For some types of inhaled medicinal aerosols (e.g. drugs with the desired systemic absorption), it may be beneficial to extend their residence time in the alveolar region, so this kind of fast transport would be undesired. Tuning the surface properties of particles (e.g. total surface area, porosity, wettability) may influence their interactions with the surfactant which can extend the residence time and improve the local bioavailability of inhaled drugs (Sosnowski T.R. et al., 2003).

The results shown in Fig. 12 confirm that local disturbance of the air/liquid interface with a model PS generates the surface tension gradient $\nabla \sigma$ and, as a consequence, the superficial flows. In Fig. 12, the surface tension gradient is produced by the unidirectional compression of the interface, and the superficial flow is illustrated by a lateral displacement of tracer particles.

Similar flows can contribute to alveolar clearance in vivo, i.e. to the effective removal of deposited particles (or particles already captured by alveolar macrophages) from alveoli as shown in Fig. 11.

Surface tension hysteresis measured in vitro for PS shown in Fig. 13 is another characteristic dynamic feature of the pulmonary surfactant, and it can be used to trace alterations in the dynamic surface tension of the PS caused by deposited particles (Kondej D. and Sosnowski T.R., 2013). In this way, physicochemical methods help to assess potential disturbance of the alveolar mass transfer caused by inhaled particles, including powder drugs (Kramek-Romanowska K. et al., 2015). The results may indicate which properties of the inhaled powders are required for the best drug bioavailability. These specific powder properties can be obtained during their production by particle engineering methods highlighted in section 3.1.

\section{Conclusions}

The main intention of this paper was to indicate important technical issues of the use of aerosolized powder particles as vehicles of drugs delivered to the lungs. Starting from the overall physical overview of the aerody-
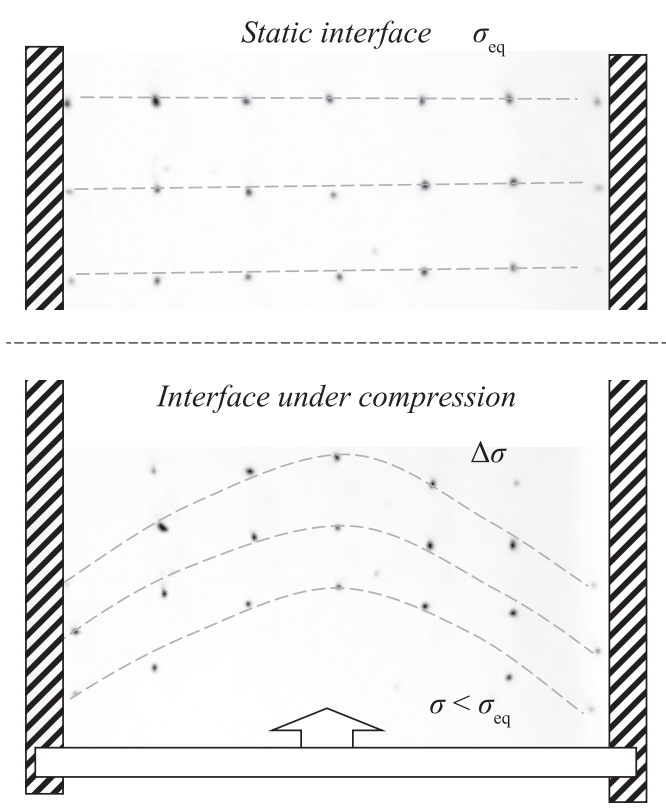

Fig. 12 Experimental results (top view of the LangmuirWilhelmy balance) showing the flow of tracer particles at the air-water surface with the phospholipid monolayer (as the model of PS) during unidirectional surface compression.

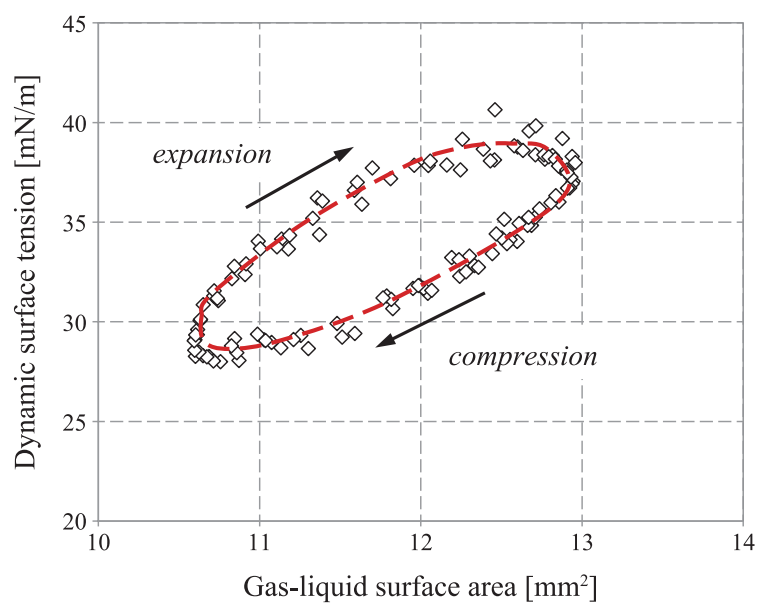

Fig. 13 Example of surface tension hysteresis recorded in the PS during oscillation of the air/liquid surface at a physiological rate and temperature (results obtained with PAT-1M device, Sinterface, Germany).

namic particle transport in the respiratory system, the importance of dynamic effects related to the non-steady airflow during breathing was pointed out. Other difficulties and uncertainties in predicting particle flow and deposition in the respiratory tract are related to the specific phenomena (e.g. particle coagulation, hygroscopic growth) which can influence the dynamic behavior of particles in the lungs. The properties of powders and the selected issues related to their preparation for inhalation purposes were briefly presented to indicate the key factors in optimizing the inhalation product. The proper design 
gtpoyver inhaling devices, i.e. DPIs, is another vital condition of successful drug delivery. Again, special attention was given here to the dynamic processes of aerosol formation and entrance into the organism. This allowed demonstration of the fact that for particles which are not drawn in sufficiently early during the inhalation phase of the breathing cycle, their deep penetration to distal lung regions will not be possible. Discussion of the unique methods of the characterization of aerosols produced in the inhalers (including DPIs) was used to indicate common misinterpretations of certain experimental data. Finally, the possibility of designing powder particles with a better pharmaceutical outcome was highlighted on the basis of a brief description of physicochemical interactions between deposited particles and lung fluids (mucus and pulmonary surfactant).

It should be realized that the physics of all processes of powder aerosolization, penetration through the respiratory system, deposition and interaction with the lung surface are so complex that we are still lacking their complete quantitative description. Classic considerations which are often based on strong simplifications overlook some key features of these processes and can lead to erroneous conclusions. It may have certain consequences in choosing the appropriate steps in product development by the pharmaceuticals industry, but also in non-optimal therapeutic decisions made by physicians. It is therefore always important to take into account the latest achievements in understanding aerosol generation from powders and their deposition in the lungs.

\section{Acknowledgements}

This scientific work was partly supported by the budget for sciences in the years 2015-2018 as Research Project No. 2014/13/B/ST8/00808. The author thanks Katarzyna Jabłczyńska, M.Sc., for preparation of the spray-dried powders and their SEM images used in this paper.

\section{Nomenclature}

$\begin{array}{ll}\text { AD } & \text { Aerosolized Dose } \\ \text { API } & \text { Active Pharmaceutical Ingredient } \\ \text { CFD } & \text { Computational Fluid Dynamics } \\ \text { COPD } & \text { Chronic Obstructive Pulmonary Disease } \\ \text { DDT } & \text { Dose Delivered to Target } \\ \text { DPI } & \text { Dry Powder Inhaler } \\ \text { ED } & \text { Emitted Dose } \\ \text { E-T } & \text { Extra-Thoracic (deposition) }\end{array}$

FPD

Fine Particle Dose

H-R High-Resistant (inhaler)

ICRP International Committee for Radiological Protection

L-R Low-Resistant (inhaler)

MD Metered Dose

MMAD Mass Median Aerodynamic Diameter

MPPD Multi-Path Particle Deposition (model)

NGI Next Generation Impactor

PIFR Peak Inspiratory Flow Rate

pMDI Pressurized Metered Dose Inhaler

PS Pulmonary Surfactant

SMI Soft Mist Inhaler

T-B Tracheo-Bronchial

TV Tidal Volume

A cross-sectional area $\left(\mathrm{m}^{2}\right)$

$C_{\mathrm{s}} \quad$ Cunningham slip correction factor (-)

$d_{\mathrm{a}} \quad$ particle aerodynamic diameter $(\mu \mathrm{m})$

$d_{\mathrm{c} i} \quad$ cut-off diameter of stage $i(\mu \mathrm{m})$

$d_{\mathrm{p}} \quad$ particle diameter $(\mu \mathrm{m})$

$F_{\mathrm{B}} \quad$ Brownian force $(\mathrm{N})$

$F_{\text {ext }} \quad$ external forces (N)

$k_{\mathrm{B}} \quad$ Boltzmann constant $\left(\mathrm{J} \mathrm{K}^{-1}\right)$

$L_{0} \quad$ characteristic length (m)

$m \quad$ mass $(\mathrm{kg})$

$\Delta P \quad$ pressure drop $(\mathrm{Pa})$

$Q \quad$ airflow rate $\left(\mathrm{m}^{3} \mathrm{~s}^{-1}\right)$

$Q_{\max } \quad$ maximum airflow rate $\left(\mathrm{m}^{3} \mathrm{~s}^{-1}\right)$

$Q_{\text {opt }} \quad$ optimum airflow rate $\left(\mathrm{m}^{3} \mathrm{~s}^{-1}\right)$

$\hat{Q} \quad$ mean airflow rate $\left(\mathrm{m}^{3} \mathrm{~s}^{-1}\right)$

$R_{\mathrm{D}} \quad$ intrinsic aerodynamic resistance of a DPI $\left(\mathrm{hPa}^{0.5} \operatorname{min~} \mathrm{L}^{-1}\right)$

Re Reynolds number (-)

$S_{0} \quad$ spectral intensity of fluctuations $\left(\mathrm{m}^{2} \mathrm{~s}^{-3}\right)$

Stk $\quad$ Stokes number (-)

$t \quad$ time (s)

$t_{\text {inh }} \quad$ time of inhalation (s)

$\Delta t \quad$ time step of numerical integration (s)

$T \quad$ temperature (K)

$u \quad$ air velocity $\left(\mathrm{m} \mathrm{s}^{-1}\right)$

$u_{\mathrm{p}} \quad$ particle velocity $\left(\mathrm{m} \mathrm{s}^{-1}\right)$

$V \quad$ inhaled volume (L) 
exponent of the correlation in NGI $(-)$

dimensionless vector $(-)$

magnitude of the acceleration of thermal excitations $\left(\mathrm{m} \mathrm{s}^{-2}\right)$

$\gamma \quad$ local resistance coefficient $(-)$

$\mu \quad$ air viscosity (Pa s)

$\rho_{\mathrm{p}} \quad$ air density $\left(\mathrm{kg} \mathrm{m}^{-3}\right)$

$\rho_{\mathrm{w}} \quad$ water density $\left(\mathrm{kg} \mathrm{m}^{-3}\right)$

$\sigma \quad$ surface tension $\left(\mathrm{N} \mathrm{m}^{-1}\right)$

$\sigma_{\mathrm{eq}} \quad$ equilibrium surface tension $\left(\mathrm{N} \mathrm{m}^{-1}\right)$

$\chi \quad$ dynamic shape factor $(-)$

\section{References}

Asgharian B., A model of deposition of hygroscopic particles in the human lung, Aerosol Science and Technology, 38 (2004) 938-947.

Asgharian B., Hofmann W., Bergmann R., Particle deposition in a multiple-path model of the human lung, Aerosol Science and Technology, 34 (2001) 332-339.

Alangari A.A., Corticosteroids in the treatment of acute asthma. Annals of Thoracic Medicine 9 (2014) 187-192.

Annals of the ICRP 24. International Commission on Radiological Protection (ICRP) Publication 66, Human respiratory tract model for radiological protection. Oxford: Elsevier Science; 1994.

ARLA. The Aerosol Research Lab of Alberta Respiratory Deposition Calculator (2008) <www.mece.ualberta.ca/arla/ deposition_calculator.html $>$ accessed 10.05.2017.

Azouz W., Chetcuti P., Hosker H.S., Saralaya D., Stephenson J., Crystyn H., The inhalation characteristics of patients when they use different dry powder inhalers. Journal of Aerosol Medicine and Pulmonary Drug Delivery, 28 (2015) 35-42.

Barnes P.J., Distribution of receptor targets in the lung, Proceedings of American Thoracic Society, 1 (2004) 345-351.

Begat P., Morton D.A., Shur J., Kippax P., Staniforth J.N., Price R., The role of force control agents in high-dose dry powder inhaler formulations, Journal of Pharmaceutical Sciences, 98 (2009) 2770-2783.

Begat P., Price R., Harris H., Morton D.A.V., Staniforth J.N., The influence of force control agents on the cohesiveadhesive balance in dry powder inhaler formulations, KONA Powder and Particle Journal, 23 (2005)109-121.

Berkenfeld K., Lamprecht A., McConville J.T., Devices for dry powder drug delivery to the lung, AAPS Pharmaceutical Science and Technology, 16 (2015) 479-490.

Borgström L., Bisgaard H., O'Callaghan C, Pedersen S., Dry-powder inhalers, in: Bisgaard H., O'Callaghan C., Smaldone G.C. (Eds.), Drug Delivery to the Lung (Lung Biology in Health and Disease), Marcel Dekker, Inc., New York-Basel, 2002, pp. 421-448.

Broday D.M., Robinson R., Application of cloud dynamics to dosimetry of cigarette smoke particles in the lungs. Aerosol Science and Technology, 37 (2003) 510-527.

Canonica G.W., Arp J., Keegstra J.R., Chrystyn H., Spiromax, a new dry powder inhaler: dose consistency under simulated real-world conditions. Journal of Aerosol Medicine and Pulmonary Drug Delivery, 28 (2015) 309-319.

Carvalho S.R., Watts A.B., Peters J.I., Williams III R.O., Dry powder inhalation for pulmonary delivery: recent advances and continuing challenges, in: Nokhodhi A., Martin G.P. (Eds.), Pulmonary Drug Delivery. Advances and Challenges (Advances in Pharmaceutical Technology), John Wiley \& Sons, Chichester, UK, 2015, pp. 35-62.

Cheng Y.S., Mechanisms of pharmaceutical aerosol deposition in the respiratory tract, AAPS Pharmaceutical Science and Technology, 15 (2014) 630-640.

Chew N.Y.K., Chan H.-K., Use of solid corrugated particles to enhance powder aerosol performance, Pharmaceutical Research, 18 (2001) 1570-1577.

CHMP (Committee for Human Medical Products), Guideline on the requirements for clinical documentation for orally inhaled products (OIP) including the requirements for demonstration of therapeutic equivalence between two inhaled products for use in the treatment of asthma and chronic obstructive pulmonary disease (COPD) in adults and for use in the treatment of asthma in children and adolescents, London: European Medicinal Agency, 2009.

Clark A.R., Borgström L., In vitro testing of pharmaceutical aerosols and predicting lung deposition from in vitro measurements, in: Bisgaard K., O'Callaghan C., Smaldone G.C. (Eds.), Drug Delivery to the Lung, Marcel Dekker, New York, 2002, pp. 105-142.

Clark A.R., Hollingworth A.M, The relationship between powder inhaler resistance and peak inspiratory conditions in healthy volunteers-implications for in vitro testing, Journal of Aerosol Medicine, 6 (1993) 99-110.

Cone R.A., Barrier properties of mucus, Advanced Drug Delivery Reviews, 61 (2009) 75-85.

Copley M., Mitchell J., Solomon D., Evaluating of the Alberta throat: an innovation to support the acquisition of more clinically applicable aerosol aerodynamic particle sized distribution (ASPD) data in oral inhaled product (OIP) development, Inhalation, 5 (2011), 12-16.

Darquenne C., Aerosol deposition in health and disease, Journal of Aerosol Medicine and Pulmonary Drug Delivery, 25 (2012) 140-147.

de Boer A.H., Gjaltema D., Hagedoorn P., Frijlink H.W., Can 'extrafine' dry powder aerosols improve lung deposition?, European Journal of Pharmaceutics and Biopharmaceutics, 96 (2015) 143-151.

de Boer A.H., Hagedoorn P., Hoppentocht M., Buttini F., Grasmeijer F., Frijlink H.W., Dry powder inhalation: past, present and future, Expert Opinion on Drug Delivery, 14 (2017) 499-512.

Dunbar C.A., Hickey A.J., Holzner P., Dispersion and characterization of pharmaceutical dry powder aerosols, KONA Powder and Particle Journal, 16 (1998) 7-45.

European Pharmacopoeia, 8th ed., Council of Europe, Strassbourg, 2013. 


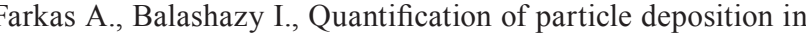
Wasymmetrical tracheobronchial model geometry, Computers in Biology and Medicine, 38 (2008) 508-518.

Finlay W.H., Martin A.R., Recent advances in predictive understanding of respiratory tract deposition, Journal of Aerosol Medicine and Pulmonary Drug Delivery, 21 (2008) 189206.

Fresconi F.E., Prasad A.K., Secondary velocity fields in the conducting airways of the human lung, Journal of Biomechanical Engineering, 129 (2007) 722-732.

Gac J., Sosnowski T.R., Gradoń L., Turbulent flow energy for aerosolization of powder particles, Journal of Aerosol Science, 39 (2008) 113-126.

Geller D.E., Weers J., Heuerding S., Development of an Inhaled Dry-Powder Formulation of Tobramycin Using PulmoSphere ${ }^{\mathrm{TM}}$ Technology, Journal of Aerosol Medicine and Pulmonary Drug Delivery, 24 (2011) 175-182.

Gradoń L., Podgórski A., Hydrodynamical model of pulmonary clearance, Chemical Engineering Science, 44 (1989) 741749.

Gradoń L., Podgórski A., Sosnowski T.R., Experimental and theoretical investigations of transport properties of DPPC monolayer, Journal of Aerosol Medicine, 9 (1996) 357-367.

Gradoń L., Sosnowski T.R., Formation of particles for dry powder inhalers, Advanced Powder Technology 25 (2014) $43-55$.

Gradoń L., Sosnowski TR, Pirożyński M, Han S., European Patent Application, (2009) EP 2340817A1Stein S.W., Thiel C.G., The history of therapeutic aerosols: a chronological review, Journal of Aerosol Medicine and Pulmonary Drug Delivery, 30 (2017) 20-41.

Healy A.M., Amaro M.I., Paluch K.J., Tajber L., Dry powders for oral inhalation free of lactose carrier particles. Advanced Drug Delivery Review 75 (2014) 32-52.

Heinemann L., The failure of Exubera: are we beating a dead horse?, Journal of Diabetes Science and Technology, 2 (2008) 518-529.

Heyder J., Svartengren M.U., Basic principles of particle behavior in the human respiratory tract, in: Bisgaard H., O'Callaghan C., Smaldone G.C. (Eds.), Drug Delivery to the Lung (Lung Biology in Health and Disease), Marcel Dekker, Inc., New York-Basel, 2002, pp. 21-45.

Hoppentocht, M., Hagedoorn, P., Frijlink, H.W., de Boer, A.H., Technological and practical challenges of dry powder inhalers and formulations, Advanced Drug Delivery Review, 75 (2014) 18-31.

Howarth P.H., Why particle size should affect clinical response to inhaled therapy, Journal of Aerosol Medicine, 14S1 (2001) S27-S34.

Islam N., Gladki E., Dry powder inhalers (DPIs) - a review of device reliability and innovation, International Journal of Pharmaceutics, 360 (2008) 1-11.

Jabłczyńska K., Janczewska M., Kulikowska A., Sosnowski T.R., Preparation and characterization of biocompatible polymer particles as potential nanocarriers for inhalation therapy, International Journal of Polymer Science, 2015 (2015) 763020 (8 pages), DOI:10.1155/2015/763020

Kaialy W., Nokhodchi A., Particle engineering for improved pulmonary drug delivery through dry powder inhalers, in: Nokhodhi A., Martin G.P. (Eds.), Pulmonary Drug Delivery. Advances and Challenges (Advances in Pharmaceutical Technology), John Wiley \& Sons, Chichester, UK, 2015, pp. 171-197.

Kleinstreuer C., Zhang Z., Donohue J.F., Targeted drug-aerosol delivery in the human respiratory system, Annual Reviews in Biomedical Engineering 10 (2008) 195-220.

Koblinger L., Hofmann W., Monte Carlo modeling of aerosol deposition in human lungs: Part I: Simulation of particle transport in a stochastic lung structure, Journal of Aerosol Science, 21 (1990) 661-674.

Kondej D., Sosnowski T.R., Alteration of biophysical activity of pulmonary surfactant by aluminosilicate nanoparticles. Inhalation Toxicology 25 (2013) 77-83.

Kondej D., Sosnowski T.R., Effect of clay nanoparticles on model lung surfactant: a potential marker of hazard from nanoaerosol inhalation. Environmental Science and Pollution Research, 23 (2016) 4660-4669.

Kramek-Romanowska K., Odziomek M., Sosnowski T.R., Dynamic tensiometry studies on interactions of novel therapeutic inhalable powders with model pulmonary surfactant at the air-water interface, Colloids Surfaces A: Physicochemical and Engineering Aspects, 480 (2015) 149-158.

Kramek-Romanowska K., Odziomek M., Sosnowski T.R., Gradon L., Effects of process variables on the properties of spray-dried mannitol and mannitol/disodium cromoglycate powders suitable for drug delivery by inhalation, Industrial and Engineering Chemistry Research, 50 (2011) 1392213931.

Kwong W.T.J., Ho S.L., Coates A.L., Comparison of nebulized particle size distribution with Malvern diffraction analyzer versus Andersen Cascade Impactor and Marple Personal Cascade Impactor, Journal of Aerosol Medicine, 13 (2000) 303-314.

Li Y.Z., Sun X., Gong T., Liu J., Zuo J., Zhang Z.R., Inhalable microparticles as carriers for pulmonary delivery of thymopentin-loaded solid lipid nanoparticles, Pharmaceutical Research, 27 (2010) 1977-1986.

Liang Z., Ni R., Zhou J., Mao S., Recent advances in controlled pulmonary drug delivery, Drug Discovery Today, 20 (2014) 380-389.

Longest P.W., Holbrook L.T., In silico models of aerosol delivery to the respiratory tract - development and applications, Advanced Drug Delivery Review, 64 (2012) 296-311.

Ma B., Lutchen K.R, CFD Simulation of aerosol deposition in an anatomically based human large-medium airway model. Annals of Biomedical Engineering, 37 (2009) 271-285.

Mao L., Wilcox D., Kippax P., Laser diffraction particle size analysis: a powerful tool for rapidly screening nebulizer formulations, Drug Delivery Technology, 10 (2010) 64-67.

Martinelli F., Balducci A.G., Rossi A., Sonvico F., Colombo P., Buttini F., "Pierce and inhale" design in capsule based dry powder inhalers: Effect of capsule piercing and motion on aerodynamic performance of drugs, International Journal of Pharmaceutics, 487 (2015), 197-204.

Matida E.A., Finlay W.H., Lange C.F., Grgic B., Improved numerical simulation of aerosol deposition in an idealized 
an $a^{0} \cdot \mathrm{r}$

de mouth-throat. Journal of Aerosol Science, 35 (2004) 1-19.

Mitchell J., Newman S., Chan H.-K., In vitro and in vivo aspects of cascade impactor tests and inhaler performance: a review, AAPS Pharmaceutical Science and Technology, 8 (2007) 237-248.

Moskal A., On Transport and Deposition of Aerosol Particles in the Human Breathing System-Selected Problems, Publishing House of Warsaw University of Technology, Poland, 2011.

Moskal A., Gradoń L., Temporary and spatial deposition of aerosol particles in the upper human airways during breathing cycle. Journal of Aerosol Science, 33 (2002) 1525-1539.

MPPD, Multiple-Path Particle Dosimetry Model v.3.04 (2015). $<$ www.ara.com/products/multiple-path-particle-dosimetry-model-mppd-v-304> accessed 10.05.2017

MSP Corporation, The Next Generation Pharmaceutical Impactor (NGI) User Guide, Shoreview, MN, USA (2008).

Nandiyanto A.B.D., Okuyama K., Progress in developing spray-drying methods for the production of controlled morphology particles: from the nanometer to submicrometer size ranges, Advanced Powder Technology, 22 (2011) 1-19.

Newman S.P., Chan H.-K., In vitro/in vivo comparisons in pulmonary drug delivery. Journal of Aerosol Medicine and Pulmonary Drug Delivery 21 (2008) 77-84.

Newman S., Peart J., Dry powder inhalers, in: Newman S. (Ed.), Respiratory Drug Delivery. Essential Theory and Practice, RDD Online/VCU, Richmond, VA, USA, 2009, pp. 257307.

Odziomek M., Kalinowska M., Płuzińska, A., Rożeń A., Sosnowski T.R., Bronchial mucus as a complex fluid: molecular interactions and influence of nanostructured particles on rheological and transport properties. Chemical and Process Engineering 38 (2017) 217-229.

Odziomek M., Sosnowski T.R., Gradoń L., Conception, preparation and properties of functional carrier particles for pulmonary drug delivery, International Journal of Pharmaceutics, 433 (2012) 51-59.

Odziomek M., Sosnowski T.R., Gradoń L., The influence of Functional Carrier Particles (FCPs) on the molecular transport rate through the reconstructed bronchial mucus - in vitro studies, Transport in Porous Media, 106 (2015) 439454.

Parra E., Pérez-Gil J., Composition, structure and mechanical properties define performance of pulmonary surfactant membranes and films, Chemistry and Physics of Lipids, 185 (2015) 153-175.

Pilcer G., Wauthoz N., Amighi K., Lactose characteristics and the generation of the aerosol, Advanced Drug Delivery Reviews, 64 (2012) 233-256.

Pirożyński M., Sosnowski T.R., Inhalation devices: from basic science to practical use, innovative vs generic products, Expert Opinion on Drug Delivery, 13 (2016) 1559-1571.

Ramachandran V., Murnane D., Hammond R.B., Pickering J., Roberts K.J., Soufian M., Forbes B., Jaffari S., Martin G.P., Collins E., Pencheva K., Formulation pre-screening of inhalation powders using computational atom-atom systematic search method, Molecular Pharmaceutics, 12 (2015) 18-33.
Sanders M., Pulmonary drug delivery: an historical overview, in: Smyth H.D.C., Hickey A.J. (Eds.), Controlled Pulmonary Drug Delivery (Advances in Delivery Science and Technology), Springer, NY-Dordrecht-Heildeberg-London, 2011, pp. 51-73.

Schuster B.S., Suk J.S., Woodworth G.F., Hanes J., Nanoparticle diffusion in respiratory mucus from humans without lung disease, Biomaterials, 34 (2013) 3439-3446.

Schum G.M., Phalen R.F., Modelling hygroscopic particle growth in human lung airways, Annals of Occupational Hygiene, 41 (1997) 60-64.

Smith D.J., Gaffney E.A., Blake J.R., A viscoelastic traction layer model of mucociliary transport, Bulletin of Mathematical Biology, 69 (2007) 289-327.

Sosnowski T.R., Powder de-aggregation in the cascade impactor, Abstracts of European Aerosol Conference, Thessaloniki, 24-29.08.2008, paper T09A035P.

Sosnowski T.R., Selected engineering and physicochemical aspects of systemic drug delivery by inhalation, Current Pharmaceutical Design, 22 (2016) 2453-2462.

Sosnowski T.R., Giżyńska K., Żywczyk Ł., Fluidization and break-up of powder particle aggregates during constant and pulsating flow in converging nozzles, Colloids Surfaces A: Physicochemical and Engineering Aspects, 441 (2014) 905-911.

Sosnowski T.R., Gradoń L., Modification of inhalable powders by pulmonary surfactant components adsorbed on droplets during spray-drying process, Colloids Surfaces A: Physicochemical and Engineering Aspects, 365 (2010) 56-61.

Sosnowski T.R., Gradoń L., Iskandar, F., Okuyama K., Interaction of deposited aerosol particles with the alveolar liquid layer, in: Gradoń L., Marijnissen J. (Eds.), Optimization of Aerosol Drug Delivery, Kluwer Academic Publishers, Dordrecht, 2003, pp. 205-216.

Sosnowski T.R., Kramek-Romanowska K., Predicted deposition of e-cigarette aerosol in the human lungs, Journal of Aerosol Medicine and Pulmonary Drug Delivery, 29 (2016) 299-309.

Sosnowski T.R., Kubski P., Wojciechowski K., New experimental model of pulmonary surfactant for biophysical studies, Colloids and Surfaces A: Physicochemical and Engineering Aspects, 519 (2017) 27-33.

Sosnowski T.R., Moskal A., Gradoń L., Mechanisms of aerosol particle deposition in the oro-pharynx under non-steady airflow, Annals of Occupational Hygiene, 51 (2007) 19-25.

Stein S.W, Thiel C.G., The history of therapeutic aerosols: a chronological review, Journal of Aerosol Medicine and Pulmonary Drug Delivery, 30 (2017) 20-41.

Tsapis N., Bennett D., Jackson B., Weitz D.A., Edwards D.A., Trojan particles: large porous carriers of nanoparticles for drug delivery, Proceedings of the National Academy of Sciences of the USA 99 (2002) 12001-12005.

Tsuda A., Henry F.S., Butler J.P., Particle transport and deposition: basic physics of particle kinetics, Comprehensive Physiology, 3 (2013), 1437-1471.

Tu J., Inthavong K., Ahmadi G.S., Computational Fluid and Particle Dynamics in The Human Respiratory System, Springer, Dordrecht, 2013. 
Lishank 0. S., Biddiscombe M.F., Barnes P.J., Regional lung

Wdeposition and bronchodilator response as a function of beta2-agonist particle size, American Journal of Respiratory and Critical Care Medicine 172 (2005) 1497-1504.

USP (United States Pharmacopeia). Aerosols, nasal sprays, metered dose inhalers and dry powder inhalers, US Pharmacopeial Convention, Rockville, 2008.

Vanbever R., Optimization of dry powder aersosols for systemic drug delivery, in: Gradoń L., Marijnissen J. (Eds.), Optimization of Aerosol Drug Delivery, Kluwer Academic Publishers, Dordrecht, 2003, pp. 91-103.

Vehring R., Expert review: pharmaceutical particle engineering via spray drying, Pharmaceutical Research, 25 (2008) 9991022.

Weber S., Zimmer A., Pardeike J., Solid Lipid Nanoparticles (SLN) and Nanostructured Lipid Carriers (NLC) for pulmonary application: A review of the state of the art, European Journal of Pharmaceutics and Biopharmaceutics, 86 (2014) 7-22.

Weers J.G., Miller D.P., Formulation design of dry powders for inhalation, Journal of Pharmaceutical Sciences, 104 (2015) 3259-3288.

Weuthen T., Roeder S., Brand P., Mullinger B., Scheuch G., In vitro testing of two formoterol dry powder inhalers at different flow rates, Journal of Aerosol Medicine, 15 (2002) 297-303.

Winkler-Heil R., Ferron G., Hofmann W., Calculation of hygroscopic particle deposition in the human lung, Inhalation Toxicology, 26 (2014) 193-206.
Wüstneck R., Wüstneck N., Moser B., Karageorgieva V., Pison U., Surface dilatational behavior of pulmonary surfactant components spread on the surface of a pendant drop. 1. Dipalmitoyl phosphatidylcholine and surfactant protein C, Langmuir, 18 (2002) 1119-1124.

Yeh H.C., Schum G.M., Models of human lung airways and their application to inhaled particle deposition, Bulletin of Mathematical Biology 42 (1980) 461-480.

Zanen P., Targetting aerosols to disease area, in: Gradoń L., Marijnissen J. (Eds.), Optimization of Aerosol Drug Delivery, Kluwer Academic Publishers, Dordrecht, 2003, pp. 243-276.

Zeng X.M., Martin G.P., Marriott C., Particulate Interactions in Dry Powder Formulations for Inhalation, CRC Press, London, 2000

Zhang Z., Kleinstreuer C., Transient airflow structures and particle transport in a sequentially branching lung airway model, Physics of Fluids, 14 (2002) 862-880.

Zhang Z., Kleinstreuer C., Donohue J.F., Kim C.S., Comparison of micro- and nano-size particle depositions in a human upper airway model. Journal of Aerosol Science, 36 (2005) 211-233.

Zhou Y., Ahuja A., Irvin C.M., Kracko D.A., McDonald J.D., Cheng Y.S., Medical nebulizer performance: effects of cascade impactor temperature, Respiratory Care, 50 (2005) 1077-1082.

Ziegler J., Wachtel H., Comparison of cascade impaction and laser diffraction for particle size distribution measurements, Journal of Aerosol Medicine, 18 (2005) 311-324.

\section{Author's short biography}

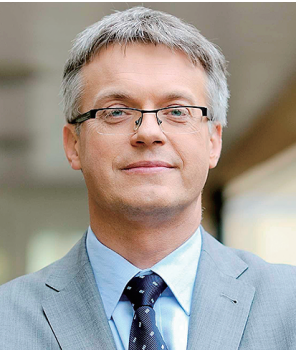

\section{Tomasz R. Sosnowski}

Tomasz R. Sosnowski received his PhD (1997) and DSc (habilitation - 2006) in chemical engineering from Warsaw University of Technology (WUT), Poland. In 1999-2000 he was a post-doc fellow at Lovelace Respiratory Research Institute in Albuquerque, USA. Currently he is a full professor at the Faculty of Chemical and Process Engineering WUT. His main scientific interests are: (i) interfacial phenomena in human lungs, including the role of the pulmonary surfactant, (ii) technical aspects of aerosol systems used in drug delivery by inhalation. He is a co-author of more than 70 scientific papers, several books and chapters, 2 granted patents and 6 patent applications. 